\title{
Significance of the Preoperative CONUT Score in Predicting Postoperative Disease-free and Overall Survival in Patients with Lung Adenocarcinoma with Obstructive Lung Disease
}

\author{
TAKAKI AKAMINE, GOUJI TOYOKAWA, TAICHI MATSUBARA, YUKA KOZUMA, \\ NAOKI HARATAKE, SHINKICHI TAKAMORI, MASAKAZU KATSURA, KAZUKI TAKADA, \\ FUMIHIRO SHOJI, TATSURO OKAMOTO and YOSHIHIKO MAEHARA
}

Department of Surgery and Science, Graduate School of Medical Sciences, Kyushu University, Fukuoka, Japan

\begin{abstract}
Background: The usefulness of the controlling nutritional status (CONUT) score for preoperative nutritional assessment has been reported in resected colorectal and esophageal cancer, but not in lung cancer with obstructive lung disease. Patients and Methods: We retrospectively reviewed 109 patients with adenocarcinoma with obstructive pulmonary disease. We set 1 as the cut-off value for the CONUT score and classified patients into high $(\geq 1)$ and low (0) CONUT groups. Results: Among 109 patients, 35 (32.1\%) had low CONUT scores, and 74 (67.8\%) had high CONUT scores. The high-CONUT group was significantly associated with a lower body mass index $(p=0.025)$ and wild-type epidermal growth factor receptor mutation status $(p=0.011)$. A multivariate analysis showed that the CONUT score was independently associated with disease-free and overall survival. Conclusion: The results of this study suggest that the CONUT score was an independent prognostic factor for disease-free and overall survival in patients with lung adenocarcinoma with obstructive lung disease.
\end{abstract}

Lung cancer is the most common cancer worldwide and has a devastating prognosis (1). Although surgical procedures, chemotherapies and molecular-targeted therapies for lung cancer have improved, the clinical outcome remains poor. Therefore, various prognostic factors have been studied. One such factor that has recently attracted substantial attention is the nutritional and immunological status, which is closely

Correspondence to: Gouji Toyokawa, Department of Surgery and Science, Graduate School of Medical Sciences, Kyushu University, 3-1-1 Maidashi, Higashi-ku, Fukuoka 812-8582, Japan. Tel: +81 926425466, Fax: +81 926425482, e-mail: gouji104kawa@gmail.com

Key Words: Controlling Nutritional Status (CONUT), lung cancer, surgery, disease-free survival, overall survival, obstructive lung disease. related to the survival of patients with malignant disease (2). Not only sarcopenia, body mass index (BMI) and changes in body weight, but also the prognostic nutritional index have been reported to affect the surgical outcomes of lung cancer (3-5). The prognostic nutritional index (PNI), which is calculated from the serum albumin concentration and total peripheral lymphocyte count, has also been reported to be associated with the survival in patients with lung cancer (68 ). We previously reported that the PNI was useful for predicting the risk of postoperative recurrence in patients with stage I non-small cell lung cancer (NSCLC) (9).

Like the PNI, the Controlling Nutritional Status (CONUT) score, another nutritional marker, is an index calculated from the serum albumin concentration and total peripheral lymphocyte count, with the addition of the total cholesterol concentration (10). The PNI score was deemed to place too much emphasis on serum albumin concentration; the CONUT score, by contrast, reduces the importance of the serum albumin concentration and newly incorporates the total cholesterol concentration, thereby leading to a more accurate evaluation of the nutritional status. While the CONUT score has been reported to be useful for the preoperative nutritional assessment in patients with resected colorectal and esophageal cancer, we reported the efficiency of the CONUT score as a prognostic factor in patients with pathological stage I NSCLC (11-14).

In patients with lung cancer with obstructive lung impairment, the nutritional status is often abnormal due to cachexia and muscle wasting. Previous reports have shown that the simultaneous presence of lung cancer and obstructive lung impairment correlated with cachexia $(15,16)$. The serum albumin levels were also found to be correlated with the pulmonary function, and high levels of cholesterol were noted in patients with severe chronic obstructive pulmonary disease (COPD) $(17,18)$. Therefore, in the present study, we focused on patients with obstructive lung disease, as obstructive lung disease may affect the nutritional status, which should be reflected in the CONUT score. 
Table I. The scoring system for Controlling Nutritional Status (CONUT).

\begin{tabular}{lcccc}
\hline & \multicolumn{4}{c}{ CONUT status } \\
\cline { 2 - 5 } Parameter & Normal & Mild & Moderate & Severe \\
\hline Serum albumin & 3.5 & $3.0-3.4$ & $2.5-2.9$ & $<2.50$ \\
Score & 0 & 2 & 4 & 6 \\
Total lymphocyte count & 1,600 & $1,200-1,599$ & $800-1,199$ & $<800$ \\
Score & 0 & 1 & 2 & 3 \\
Total cholesterol & 180 & $140-179$ & $100-139$ & $<100$ \\
Score & 0 & 1 & 2 & 3 \\
\hline Total score & $0-1$ & $2-4$ & $5-8$ & $9-12$ \\
\hline
\end{tabular}

The aim of this study was to evaluate the utility of the preoperative CONUT score in predicting the postoperative disease-free (DFS) and overall (OS) survival in patients with lung adenocarcinoma with obstructive lung disease.

\section{Patients and Methods}

From January 2003 to December 2012, 428 consecutive patients with primary lung adenocarcinoma underwent complete surgery at the Department of Surgery and Science, Graduate School of Medical Sciences, Kyushu University. We retrospectively selected 109 patients with adenocarcinoma and obstructive pulmonary disease whose preoperative spirometry showed a forced expiratory volume in $1 \mathrm{~s}$ (FEV1) to forced vital capacity (FVC) ratio of less than $70 \%$. The histological diagnosis of the tumors was based on the criteria of the World Health Organization and the seventh edition of the TNM classification system of the American Joint Committee on Cancer. Preoperative variables, such as age, sex, smoking status, BMI, CONUT score, and carcinoembryonic antigen (CEA) and epidermal growth factor receptor $(E G F R)$ status were evaluated. The $E G F R$ status had been determined in tumor tissue using the peptide nucleic acid-locked nucleic acid polymerase chain reaction clamp method (Mitsubishi Chemical Medicine, Tokyo, Japan) (19).

Follow-up. The patients were followed up every 3-4 months for the initial 2 years, every 6 months for the next 3 years, and annually thereafter. They underwent medical checkups and chest X-ray or computed tomography. All patients were followed-up until April 2016 or until their death.

DFS and OS. The primary and secondary outcomes were the DFS and OS, respectively. The OS was defined as the time from the day of surgery until the last follow-up or death. The DFS was defined as the time from the day of surgery to the date of the last normal follow-up for patients without recurrence, or to the date of the first detection of a recurring lesion for patients with recurrence. In patients with no evidence of recurrence, DFS was censored at the date of death or last follow-up.

CONUT evaluation. The CONUT score was calculated using the serum albumin concentration, peripheral lymphocyte count and the
Table II. Clinicopathological characteristics of 109 patients with obstructive lung impairment.

\begin{tabular}{|c|c|c|}
\hline Factor & & Value \\
\hline \multirow[t]{2}{*}{ Age (years) } & Median & 72 \\
\hline & Range & $45-85$ \\
\hline \multirow[t]{2}{*}{ Gender, $\mathrm{n}$} & Female & 33 \\
\hline & Male & 76 \\
\hline \multirow[t]{2}{*}{ Smoking status, $\mathrm{n}$} & Never-smoker & 35 \\
\hline & Smoker & 74 \\
\hline \multirow{2}{*}{ Body mass index } & $\geq 20 \mathrm{~kg} / \mathrm{m}^{2}$ & 85 \\
\hline & $<20 \mathrm{~kg} / \mathrm{m}^{2}$ & 24 \\
\hline \multirow[t]{2}{*}{ CONUT score } & 0 & 35 \\
\hline & $\geq 1$ & 74 \\
\hline \multirow[t]{2}{*}{ CEA ng/ml } & Median & 3.5 \\
\hline & Range & $0.7-115$ \\
\hline \multirow[t]{4}{*}{ Pathological $\mathrm{T}$ status, $\mathrm{n}$} & 1 & 54 \\
\hline & 2 & 44 \\
\hline & 3 & 9 \\
\hline & 4 & 2 \\
\hline \multirow[t]{4}{*}{ Pathological $\mathrm{N}$ status, $\mathrm{n}$} & 0 & 90 \\
\hline & 1 & 11 \\
\hline & 2 & 8 \\
\hline & 3 & 0 \\
\hline \multirow[t]{4}{*}{ Pathological stage, $n$} & I & 74 \\
\hline & II & 24 \\
\hline & III & 9 \\
\hline & IV & 2 \\
\hline \multirow[t]{3}{*}{ Tumor grade, $\mathrm{n}$} & 1 & 49 \\
\hline & 2 & 40 \\
\hline & 3 & 20 \\
\hline \multirow[t]{2}{*}{ Pleural invasion, $\mathrm{n}$} & Negative & 79 \\
\hline & Positive & 29 \\
\hline \multirow[t]{2}{*}{ Lymphatic invasion, $\mathrm{n}$} & Negative & 95 \\
\hline & Positive & 14 \\
\hline \multirow[t]{2}{*}{ Vascular invasion, $\mathrm{n}$} & Negative & 74 \\
\hline & Positive & 35 \\
\hline \multirow[t]{2}{*}{ Histological subtype, $\mathrm{n}$} & AAH/AIS/MIA/ lipidic & 15 \\
\hline & Other** & 94 \\
\hline \multirow[t]{3}{*}{ Surgical procedure, $\mathrm{n}$} & Sublobar resection & 32 \\
\hline & Lobectomy & 75 \\
\hline & Pneumonectomy & 2 \\
\hline \multirow{2}{*}{ EGFR, n* } & Wild-type & 41 \\
\hline & Mutant & 32 \\
\hline
\end{tabular}

CONUT, Controlling Nutrition Status; CEA, carcinoembryonic antigen; AAH: atypical adenomatous hyperplasia; AIS: adenocarcinoma in situ; MIA: minimally invasive adenocarcinoma; $E G F R$ : epidermal growth factor receptor. ${ }^{*}$ Cases for which data were available. **Papillary predominant, acinar predominant, micropapillary predominant, solid predominant and variants.

total cholesterol concentration (Table I). Preoperative blood samples were obtained routinely before surgery. To determine the cut-off value for the CONUT score, we used a receiver operating characteristic (ROC) curve. The curve identified an optimal CONUT cut-off value of 1 (area under the curve of 0.596 ; sensitivity of 0.6711 and specificity of 0.4375 , as shown in Figure 1). Therefore, we set 1 as the cut-off value for the CONUT score in this study and classified patients into high CONUT $(\geq 1)$ and low CONUT (0) groups. 


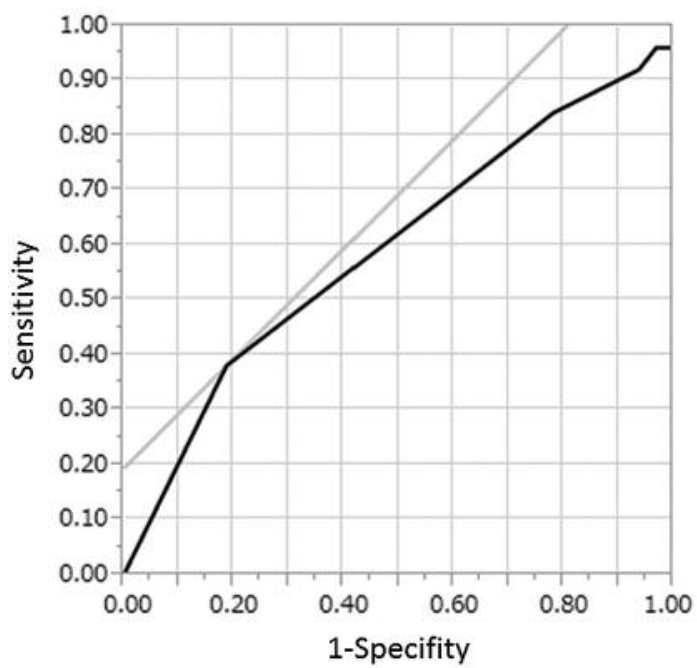

Figure 1. The receiver operating characteristic curve for the Controlling Nutritional Status (CONUT). The curve identified an optimal CONUT cut-off value of 1 (area under curve of 0.596; sensitivity of 0.6711 and specificity of 0.4375).

Statistical analysis. Statistical analyses for the categorical factors were performed using Fisher's exact tests. The DFS and OS rates were estimated using the Kaplan-Meier method with the log-rank test. Univariate and multivariate analyses with a Cox proportional hazards model or logistic regression model were performed to assess the significant factors. We used the JMP Statistical Discovery software program (version 11.0; SAS Institute, Cary, NC, USA) for the statistical analyses. When a $p$-value was less than 0.05 , we considered the results statistically significant.

\section{Results}

Patient characteristics. The patient characteristics are summarized in Table II. The patients ranged in age from 45 to 85 years (mean, 72 years). There were 76 men and 33 women. The median BMI was $22.3 \mathrm{~kg} / \mathrm{m}^{2}$. Patients with high $(\geq 20)$ and low BMI $(<20)$ accounted for $78 \%(n=85)$ and $22 \%(n=24)$, respectively. The histological subtypes of adenocarcinoma were atypical adenomatous hyperplasia, adenocarcinoma in situ, minimally invasive adenocarcinoma and lepidic predominant in 15 cases $(13.7 \%)$ and other types in the remainder $(86.3 \%)$. Pathological stage I disease was confirmed in 74 patients $(67.9 \%)$, and stage II, III or IV disease was confirmed in 35 patients $(32.1 \%)$. Pathological N0 disease was confirmed in 90 patients $(82.5 \%)$, and N1 or N2 disease was confirmed in 19 patients $(17.5 \%)$. The $E G F R$ status was available for 73 patients; of these, 41 (56.2\%) had wild-type $E G F R$, and 33 (43.8\%) had mutant EGFR.

Correlation between CONUT scores and other clinicopathological findings. The clinicopathological characteristics of the
Table III. Association between the Controlling Nutrition Status (CONUT) score and clinicopathological factors in patients with obstructive lung impairment.

\begin{tabular}{|c|c|c|c|c|}
\hline \multirow[t]{2}{*}{ Factor } & \multirow[t]{2}{*}{$\mathrm{n}$} & \multicolumn{2}{|c|}{ CONUT score } & \multirow[t]{2}{*}{$p$-Value } \\
\hline & & 0 & $\geq 1$ & \\
\hline \multicolumn{5}{|l|}{ Age } \\
\hline$<70$ Years & 40 & 17 & 23 & \multirow[t]{2}{*}{0.091} \\
\hline$\geq 70$ Years & 69 & 18 & 51 & \\
\hline \multicolumn{5}{|l|}{ Gender } \\
\hline Female & 33 & 12 & 21 & \multirow[t]{2}{*}{0.656} \\
\hline Male & 76 & 23 & 53 & \\
\hline \multicolumn{5}{|l|}{ Smoking history } \\
\hline Never-smoker & 35 & 13 & 22 & \multirow[t]{2}{*}{0.512} \\
\hline Smoker & 74 & 22 & 52 & \\
\hline \multicolumn{5}{|l|}{ Body mass index } \\
\hline$\geq 20 \mathrm{~kg} / \mathrm{m}^{2}$ & 85 & 32 & 53 & \multirow[t]{2}{*}{0.025} \\
\hline$<20 \mathrm{~kg} / \mathrm{m}^{2}$ & 24 & 3 & 21 & \\
\hline \multicolumn{5}{|l|}{ CEA } \\
\hline$\leq 3.2 \mathrm{ng} / \mathrm{ml}$ & 51 & 21 & 30 & \multirow[t]{2}{*}{0.099} \\
\hline$>3.2 \mathrm{ng} / \mathrm{ml}$ & 56 & 14 & 42 & \\
\hline \multicolumn{5}{|l|}{ Pathological T status } \\
\hline 1 & 54 & 20 & 34 & \multirow[t]{2}{*}{0.310} \\
\hline$\geq 2$ & 55 & 15 & 40 & \\
\hline \multicolumn{5}{|l|}{ Pathological N status } \\
\hline 0 & 90 & 29 & 61 & \multirow[t]{2}{*}{1.000} \\
\hline$\geq 1$ & 19 & 6 & 13 & \\
\hline \multicolumn{5}{|l|}{ Tumor grade } \\
\hline 1 & 49 & 17 & 32 & \multirow[t]{2}{*}{0.682} \\
\hline 2,3 & 60 & 18 & 42 & \\
\hline \multicolumn{5}{|l|}{ Pleural invasion } \\
\hline Negative & 79 & 26 & 53 & \multirow[t]{2}{*}{1.000} \\
\hline Positive & 29 & 9 & 20 & \\
\hline \multicolumn{5}{|l|}{ Lymphatic invasion } \\
\hline Negative & 95 & 31 & 64 & \multirow[t]{2}{*}{1.000} \\
\hline Positive & 14 & 4 & 10 & \\
\hline \multicolumn{5}{|l|}{ Vascular invasion } \\
\hline Negative & 74 & 26 & 48 & 0.384 \\
\hline Positive & 35 & 9 & 26 & \\
\hline Histological subtype & & & & \\
\hline AAH/AIS/MIA/lepidic & 15 & 4 & 11 & 0.770 \\
\hline Other** & 94 & 31 & 63 & \\
\hline Surgical procedure & & & & \\
\hline Sublobar & 32 & 13 & 19 & 0.262 \\
\hline$\geq$ Lobectomy & 77 & 22 & 55 & \\
\hline$E G F R^{*}$ & & & & \\
\hline Wild-type & 41 & 8 & 33 & 0.011 \\
\hline Mutant & 32 & 16 & 16 & \\
\hline
\end{tabular}

CONUT, Controlling Nutrition Status; CEA, carcinoembryonic antigen; AAH: atypical adenomatous hyperplasia; AIS: adenocarcinoma in situ; MIA: minimally-invasive adenocarcinoma; EGFR: epidermal growth factor receptor. ${ }^{*}$ Cases for which data were available. **Papillary predominant, acinar predominant, micropapillary predominant, solid predominant and variants.

two CONUT groups are shown in Table III. The high-CONUT group was significantly associated with a lower BMI $(p=0.025)$ and wild-type $E G F R$ mutation status ( $p=0.011)$. 
A

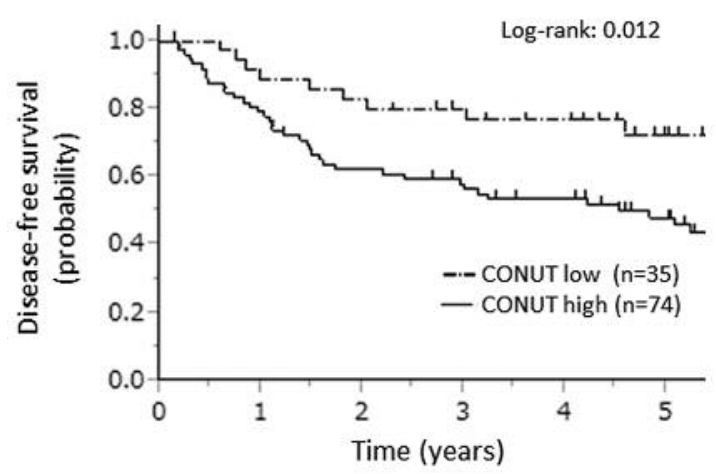

B

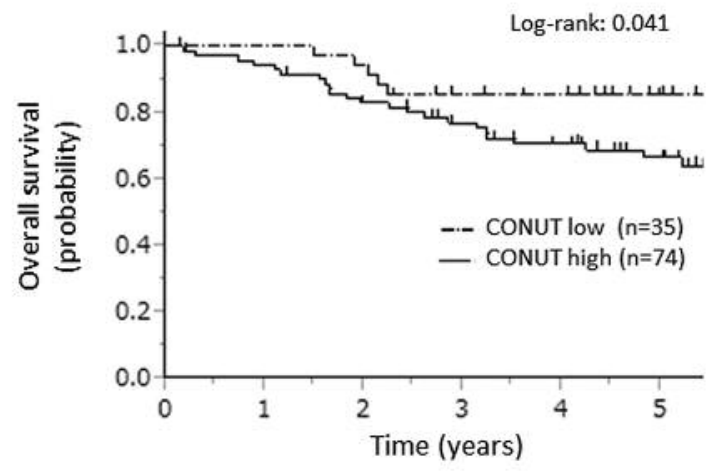

Figure 2. Kaplan-Meier curves showing the disease-free (A) and overall (B) survival of patients with adenocarcinoma with obstructive pulmonary disease according to the Controlling Nutritional Status (CONUT) score.
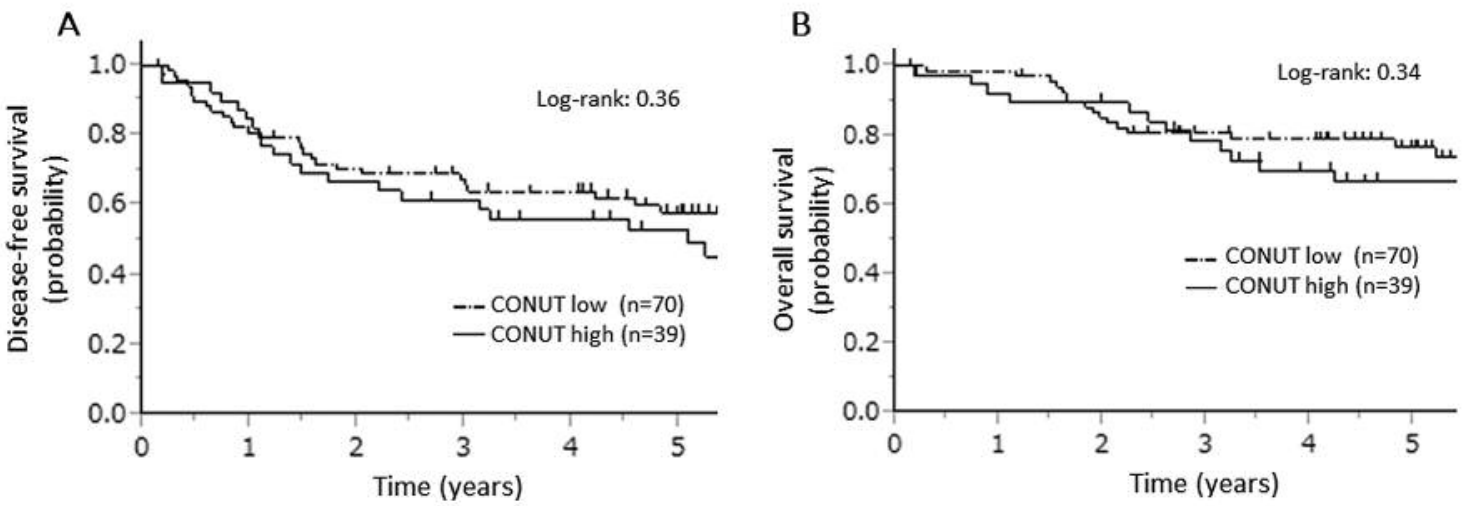

Figure 3. Kaplan-Meier curves showing the disease-free (A) and overall $(B)$ survival of patients with adenocarcinoma with obstructive pulmonary disease according to the Controlling Nutritional Status (CONUT) score with the cut-off score set at 2.

Survival analyses according to the CONUT score. The fiveyear DFS rates in the low- and high-CONUT groups were $72.0 \%$ and $48.1 \%$, respectively (Figure $2 \mathrm{~A}$ ), with a significant difference between the groups $(p=0.012)$. The 5 -year OS rates in the low- and high-CONUT groups were $85.7 \%$ and $66.7 \%$, respectively (Figure $2 \mathrm{~B}$ ), and there was a significant difference between the groups $(p=0.041)$. However, when the cut-off score was set at 2 , there was no significant association between the CONUT score and the DFS and OS (Figure 3).

Univariate and multivariate analyses for the relationship between DFS and clinicopathological factors. The correlations between DFS and clinicopathological factors are shown in Table IV. In the univariate analysis, the CONUT score, CEA, pathological tumor status, pathological nodal status, grade, pleural invasion and lymphatic vessel invasion were significantly positively associated with the DFS. A multivariate analysis showed that the CONUT score $(p=0.004)$, pathological nodal status $(p=0.012)$, grade $(p=0.034)$ and lymphatic vessel invasion $(p<0.001)$ were independently positively associated with the DFS.

Univariate and multivariate analyses for the relationship between $O S$ and clinicopathological factors. The correlations between the OS and clinicopathological factors are shown in Table V. In the univariate analyses, age, the CONUT score, CEA, pathological tumor status, nodal status, grade, pleural invasion lymphatic vessel invasion and histological subtype were significantly positively associated with the OS. A multivariate analysis showed that age $(p=0.001)$, the CONUT score $(p=0.037)$, CEA $(p=0.010)$, pathological tumor status $(p=0.037)$, pathological nodal status $(p=0.007)$ and grade $(p=0.016)$ were independently positively associated with the OS. 
Table IV. Univariate and multivariate analyses for the relationship between the disease-free survival and clinicopathological factors.

\begin{tabular}{|c|c|c|c|c|c|c|c|}
\hline \multirow[t]{2}{*}{ Factor } & \multirow[t]{2}{*}{$\mathrm{N}$} & \multicolumn{3}{|c|}{ Univariate analysis } & \multicolumn{3}{|c|}{ Multivariate analysis } \\
\hline & & HR & $95 \% \mathrm{CI}$ & $p$-Value & HR & $95 \% \mathrm{CI}$ & $p$-Value \\
\hline \multicolumn{8}{|l|}{ Age } \\
\hline$<70$ Years & 40 & 1.000 & & & & & \\
\hline$\geq 70$ Years & 69 & 1.131 & $0.638-2.080$ & 0.6783 & & & \\
\hline \multicolumn{8}{|l|}{ Gender } \\
\hline Female & 33 & 1.000 & & & & & \\
\hline Male & 76 & 1.417 & $0.773-2.771$ & 0.267 & & & \\
\hline \multicolumn{8}{|l|}{ Smoking history } \\
\hline Never-smoker & 35 & 1.000 & & & & & \\
\hline Smoker & 74 & 0.879 & $0.496-1.615$ & 0.667 & & & \\
\hline \multicolumn{8}{|l|}{ Body mass index } \\
\hline$\geq 20 \mathrm{~kg} / \mathrm{m}^{2}$ & 85 & 1.000 & & & & & \\
\hline$<20 \mathrm{~kg} / \mathrm{m}^{2}$ & 24 & 1.026 & $0.484-1.978$ & 0.942 & & & \\
\hline \multicolumn{8}{|l|}{ CONUT score } \\
\hline 0 & 35 & 1.000 & & & 1.000 & & \\
\hline$\geq 1$ & 74 & 2.359 & $1.228-4.992$ & 0.009 & 2.631 & $1.335-5.683$ & 0.004 \\
\hline \multicolumn{8}{|l|}{ CEA } \\
\hline$\leq 3.2 \mathrm{ng} / \mathrm{ml}$ & 51 & 1.000 & & & 1.000 & & \\
\hline$>3.2 \mathrm{ng} / \mathrm{ml}$ & 56 & 3.360 & $1.831-6.575$ & $<0.001$ & 1.709 & $0.880-3.509$ & 0.116 \\
\hline \multicolumn{8}{|l|}{ Pathological T status } \\
\hline 1 & 54 & 1.000 & & & 1.000 & & \\
\hline$\geq 2$ & 55 & 2.122 & $1.210-3.801$ & 0.009 & 1.935 & $0.903-4.030$ & 0.088 \\
\hline \multicolumn{8}{|l|}{ Pathological N status } \\
\hline 0 & 90 & 1.000 & & & 1.000 & & \\
\hline$\geq 1$ & 19 & 3.954 & $2.129-7.086$ & $<0.001$ & 2.529 & $1.240-5.007$ & 0.012 \\
\hline \multicolumn{8}{|l|}{ Tumor grade } \\
\hline 1 & 49 & 1.000 & & & 1.000 & & \\
\hline 2,3 & 60 & 2.470 & $1.372-4.670$ & 0.002 & 1.998 & $1.052-3.960$ & 0.034 \\
\hline \multicolumn{8}{|l|}{ Pleural invasion } \\
\hline Negative & 79 & 1.000 & & & 1.000 & & \\
\hline Positive & 29 & 2.368 & $1.278-4.243$ & 0.007 & 0.794 & $0.346-1.860$ & 0.591 \\
\hline \multicolumn{8}{|l|}{ Lymphatic invasion } \\
\hline Negative & 95 & 1.000 & & & 1.000 & & \\
\hline Positive & 14 & 6.592 & $3.352-12.364$ & $<0.001$ & 4.117 & $1.839-8.837$ & $<0.001$ \\
\hline \multicolumn{8}{|l|}{ Vascular invasion } \\
\hline Negative & 74 & 1.000 & & & & & \\
\hline Positive & 35 & 1.599 & $0.886-2.809$ & 0.116 & & & \\
\hline \multicolumn{8}{|l|}{ Histological subtype } \\
\hline AAH/AIS/MIA/lepidic & 15 & 1.000 & & & 1.000 & & \\
\hline Other** & 94 & 3.257 & $1.190-13.432$ & 0.018 & 1.386 & $0.449-6.065$ & 0.599 \\
\hline \multicolumn{8}{|l|}{ Surgical procedure } \\
\hline Sublobar & 32 & 1.000 & & & & & \\
\hline$\geq$ Lobectomy & 77 & 1.809 & $0.958-3.718$ & 0.069 & & & \\
\hline \multicolumn{8}{|l|}{$E G F R^{*}$} \\
\hline Wild-type & 41 & 1.000 & & & & & \\
\hline Mutant & 32 & 0.835 & $0.403-1.678$ & 0.615 & & & \\
\hline
\end{tabular}

CONUT, Controlling Nutrition Status; CEA, carcinoembryonic antigen; AAH: atypical adenomatous hyperplasia; AIS: adenocarcinoma in situ; MIA: minimally-invasive adenocarcinoma; EGFR: epidermal growth factor receptor. *Cases for which data were available. **Papillary predominant, acinar predominant, micropapillary predominant, solid predominant and variants.

\section{Discussion}

Many studies have investigated the prognostic significance of inflammatory markers and nutritional status, such as PNI and CONUT, in patients with cancer. Among these markers, the efficiency of CONUT score for predicting the likelihood of survival or other events has been increasingly reported not only in patients with heart failure or liver failure, but also 
Table V. Univariate and multivariate analyses for the relationship between the overall survival and the clinicopathological factors.

\begin{tabular}{|c|c|c|c|c|c|c|c|}
\hline \multirow[t]{2}{*}{ Factors } & \multirow[t]{2}{*}{$\mathrm{N}$} & \multicolumn{3}{|c|}{ Univariate analysis } & \multicolumn{3}{|c|}{ Multivariate analysis } \\
\hline & & $\mathrm{HR}$ & $95 \% \mathrm{CI}$ & $p$-Value & HR & $95 \% \mathrm{CI}$ & $p$-Value \\
\hline \multicolumn{8}{|l|}{ Age } \\
\hline$<70$ Years & 40 & 1.000 & & & 1.000 & & \\
\hline$\geq 70$ Years & 69 & 2.288 & $1.043-5.738$ & 0.038 & 4.402 & $1.841-11.946$ & 0.001 \\
\hline \multicolumn{8}{|l|}{ Gender } \\
\hline Female & 33 & 1.000 & & & & & \\
\hline Male & 76 & 1.424 & $0.667-3.390$ & 0.374 & & & \\
\hline \multicolumn{8}{|l|}{ Smoking history } \\
\hline Never-smoker & 35 & 1.000 & & & & & \\
\hline Smoker & 74 & 1.221 & $0.584-2.787$ & 0.606 & & & \\
\hline \multicolumn{8}{|l|}{ Body mass index } \\
\hline$\geq 20 \mathrm{~kg} / \mathrm{m}^{2}$ & 85 & 1.000 & & & & & \\
\hline$<20 \mathrm{~kg} / \mathrm{m}^{2}$ & 24 & 1.238 & $0.493-2.726$ & 0.626 & & & \\
\hline \multicolumn{8}{|l|}{ CONUT score } \\
\hline 0 & 35 & 1.000 & & & 1.000 & & \\
\hline$\geq 1$ & 74 & 2.449 & $1.077-6.583$ & 0.032 & 2.637 & $1.058-7.802$ & 0.037 \\
\hline \multicolumn{8}{|l|}{ CEA } \\
\hline$\leq 3.2 \mathrm{ng} / \mathrm{ml}$ & 51 & 1.000 & & & 1.000 & & \\
\hline$>3.2 \mathrm{ng} / \mathrm{ml}$ & 56 & 3.859 & $1.760-9.675$ & 0.005 & 3.019 & $1.285-8.004$ & 0.010 \\
\hline \multicolumn{8}{|l|}{ Pathological T status } \\
\hline 1 & 54 & 1.000 & & & 1.000 & & \\
\hline$\geq 2$ & 55 & 3.045 & $1.472-6.758$ & 0.002 & 2.671 & $1.063-6.831$ & 0.037 \\
\hline \multicolumn{8}{|l|}{ Pathological N status } \\
\hline 0 & 90 & 1.000 & & & 1.000 & & \\
\hline$\geq 1$ & 19 & 4.081 & $1.930-8.273$ & $<0.001$ & 3.677 & $1.458-9.163$ & 0.007 \\
\hline \multicolumn{8}{|l|}{ Tumor grade } \\
\hline 1 & 49 & 1.000 & & & 1.000 & & \\
\hline 2,3 & 60 & 2.977 & $1.393-7.090$ & 0.004 & 2.698 & $1.195-6.745$ & 0.016 \\
\hline \multicolumn{8}{|l|}{ Pleural invasion } \\
\hline Negative & 79 & 1.000 & & & 1.000 & & \\
\hline Positive & 29 & 2.191 & $1.013-4.486$ & 0.047 & 0.522 & $0.202-1.319$ & 0.168 \\
\hline \multicolumn{8}{|l|}{ Lymphatic invasion } \\
\hline Negative & 95 & 1.000 & & & 1.000 & & \\
\hline Positive & 14 & 3.677 & $1.598-7.762$ & 0.003 & 2.260 & $0.834-5.624$ & 0.105 \\
\hline \multicolumn{8}{|l|}{ Vascular invasion } \\
\hline Negative & 74 & 1.000 & & & & & \\
\hline Positive & 35 & 2.022 & $0.987-4.058$ & 0.054 & & & \\
\hline \multicolumn{8}{|l|}{ Histological subtype } \\
\hline AAH/AIS/MIA/lepidic & 15 & 1.000 & & & 1.000 & & \\
\hline Other** & 94 & 5.973 & $1.282-106.313$ & 0.017 & 2.594 & $0.481-48.150$ & 0.310 \\
\hline \multicolumn{8}{|l|}{ Surgical procedure } \\
\hline Sublobar & 32 & 1.000 & & & & & \\
\hline$\geq$ Lobectomy & 77 & 1.392 & $0.652-3.311$ & 0.406 & & & \\
\hline \multicolumn{8}{|l|}{$E G F R^{*}$} \\
\hline Wild-type & 41 & 1.000 & & & & & \\
\hline Mutant & 32 & 0.464 & $0.165-1.143$ & 0.097 & & & \\
\hline
\end{tabular}

CONUT, Controlling Nutrition Status; CEA, carcinoembryonic antigen; AAH: atypical adenomatous hyperplasia; AIS: adenocarcinoma in situ; MIA: minimally-invasive adenocarcinoma; EGFR: epidermal growth factor receptor. *Cases for which data were available. **Papillary predominant, acinar predominant, micropapillary predominant, solid predominant and variants.

those with cancer $(20,21)$. The CONUT score may also be useful in predicting the treatment outcomes such as the survival for patients with lung cancer; however, its utility has yet to be evaluated. We found that the CONUT score was useful for predicting postoperative survival in patients with stage I NSCLC (unpublished data). Furthermore, as in patients with lung cancer without any complications, the preoperative CONUT score is also expected to be useful in 
predicting the outcomes of treatment in patients with respiratory complications, such as COPD or interstitial pneumonia. In this study, the prognostic influence of the CONUT score was evaluated in 109 patients with adenocarcinoma with obstructive pulmonary disease. We found that the CONUT score was an independent prognostic factor for the DFS and OS, demonstrating the importance of the preoperative nutritional status in patients with lung cancer with obstructive pulmonary disease.

The need for preoperative nutritional intervention in patients with cancer should be emphasized. Several studies have demonstrated the significance of a good nutritional status prior to therapeutic intervention in patients with esophageal cancer, head and neck cancer and NSCLC (22$26)$. With regard to patients with lung cancer, a systematic review suggested that exercise and nutritional interventions may have beneficial effects on unintentional weight loss and physical strength in patients with advanced NSCLC (26). However, the optimum intervention for improving the nutritional status has yet to be established. Preoperative nutritional intervention based on the CONUT score may be a factor which could contribute to improved survival and should be assessed in future studies.

Although the CONUT score was found to be useful as a prognostic factor, it may also have other potential roles. For example, since the CONUT score includes the total lymphocyte count, it reflects the immune status and may, therefore, be a useful marker for immunotherapy.

Immunotherapy has emerged as a promising strategy for cancer treatment. Immune checkpoint inhibitors were recently shown to improve the prognoses in multiple types of cancer $(27,28)$. With regard to lung cancer, nivolumab, a programmed death-1 (PD-1) immune checkpoint inhibitor, has been approved in many countries; programmed deathligand 1 (PD-L1) expression is, therefore, expected to serve as a useful biomarker for predicting the antitumor efficacy of antibodies against PD-1 or PD-L1. However, studies are ongoing to identify other useful biomarkers, which is one of the greatest challenges in studies of immune checkpoint inhibitors. For example, the absolute lymphocyte count has been shown to be a specific biomarker of ipilimumab, which is an antibody targeting cytotoxic T-lymphocyte-associated antigen 4 for melanoma (29). If the CONUT score can be used as a predictive factor for nivolumab efficacy, it may serve as a convenient and noninvasive marker in the prediction of the efficacy of this compound. However, at present, such uses are entirely speculative and not based on any data; further investigations are therefore needed.

Several limitations associated with the present study warrant mention. This was a retrospective study conducted at a single Institute, and all enrolled patients had adenocarcinoma. Further studies including patients with not only adenocarcinoma but also squamous cell carcinoma should be performed to confirm our findings. The CONUT score is convenient and useful for evaluating both the immunological and nutritional status. The results of this study suggest that the CONUT score is an independent prognostic factor for DFS and OS in patients with lung adenocarcinoma with obstructive lung disease.

\section{Acknowledgements}

The Authors thank Brian Quinn for his critical comments on the manuscript.

\section{References}

1 Torre LA, Bray F, Siegel RL, Ferlay J, Lortet-Tieulent J and Jemal A: Global cancer statistics, 2012. CA Cancer J Clin 65: 87-108, 2015.

2 Kanda M, Fujii T, Kodera Y, Nagai S, Takeda S and Nakao A: Nutritional predictors of postoperative outcome in pancreatic cancer. Br J Surg 98: 268-274, 2011.

3 Kinsey CM, San Jose Estepar R, van der Velden J, Cole BF, Christiani DC and Washko GR: Lower pectoralis muscle area is associated with a worse overall survival in non-small cell lung cancer. Cancer Epidemiol Biomarkers Prev 26: 38-43, 2017.

4 Suzuki Y, Okamoto T, Fujishita T, Katsura M, Akamine T, Takamori S, Morodomi Y, Tagawa T, Shoji F and Maehara Y: Clinical implications of sarcopenia in patients undergoing complete resection for early non-small cell lung cancer. Lung Cancer 101: 92-97, 2016.

5 Nakagawa T, Toyazaki T, Chiba N, Ueda $\mathrm{Y}$ and Gotoh M: Prognostic value of body mass index and change in body weight in postoperative outcomes of lung cancer surgery. Interact Cardiovasc Thorac Surg 23: 560-566, 2016.

6 Mori S, Usami N, Fukumoto K, Mizuno T, Kuroda H, Sakakura $\mathrm{N}$, Yokoi K and Sakao Y: The significance of the Prognostic Nutritional Index in patients with completely resected non-small cell lung cancer. PLoS One 10: e0136897, 2015.

7 Shimizu K, Okita R, Saisho S, Maeda A, Nojima Y and Nakata M: Preoperative neutrophil/lymphocyte ratio and prognostic nutritional index predict survival in patients with non-small cell lung cancer. World J Surg Oncol 13: 291, 2015.

8 Sheng J, Yang YP, Ma YX, Qin T, Hu ZH, Hong SD, Zhou T, Huang Y, Zhao HY and Zhang L: Low Prognostic Nutritional Index correlates with worse survival in patients with advanced NSCLC following EGFR-TKIs. PLoS One 11: e0147226, 2016.

9 Shoji F, Morodomi Y, Akamine T, Takamori S, Katsura M, Takada K, Suzuki Y, Fujishita T, Okamoto T and Maehara Y: Predictive impact for postoperative recurrence using the preoperative prognostic nutritional index in pathological stage I non-small cell lung cancer. Lung Cancer 98: 15-21, 2016.

10 de Ulibarri Perez JI, Fernandez G, Rodriguez Salvanes F and Diaz Lopez AM: Nutritional screening; control of clinical undernutrition with analytical parameters. Nutr Hosp 29: 797-811, 2014.

11 Iseki Y, Shibutani M, Maeda K, Nagahara H, Ohtani H, Sugano K, Ikeya T, Muguruma K, Tanaka H, Toyokawa T, Sakurai K and Hirakawa K: Impact of the preoperative Controlling Nutritional Status (CONUT) Score on the survival after curative surgery for colorectal cancer. PLoS One 10: e0132488, 2015. 
12 Toyokawa T, Kubo N, Tamura T, Sakurai K, Amano R, Tanaka H, Muguruma K, Yashiro M, Hirakawa K and Ohira M: The pretreatment Controlling Nutritional Status (CONUT) score is an independent prognostic factor in patients with resectable thoracic esophageal squamous cell carcinoma: results from a retrospective study. BMC Cancer 16: 722, 2016.

13 Yoshida N, Baba Y, Shigaki H, Harada K, Iwatsuki M, Kurashige J, Sakamoto Y, Miyamoto Y, Ishimoto T, Kosumi K, Tokunaga R, Imamura Y, Ida S, Hiyoshi Y, Watanabe M and Baba H: Preoperative nutritional assessment by Controlling Nutritional Status (CONUT) is useful to estimate postoperative morbidity after esophagectomy for esophageal cancer. World J Surg 40: 1910-1917, 2016.

14 Shoji F, Haratake N, Akamine T, Takamori S, Katsura M, Takada $\mathrm{K}$, Toyokawa G, Okamoto $\mathrm{T}$ and Maehara $\mathrm{Y}$ : The preoperative Controlling Nutritional Status score predicts survival after curative surgery in patients with pathological stage I non-small cell lung cancer. Anticancer Res 37: 741-747, 2017.

15 Sanders KJ, Kneppers AE, van de Bool C, Langen RC and Schols AM: Cachexia in chronic obstructive pulmonary disease: new insights and therapeutic perspective. J Cachexia Sarcopenia Muscle 7: 5-22, 2016.

16 Shiono M, Huang K, Downey RJ, Consul N, Villanueva N, Beck K, Fenn K, Dietz D, Yamaguchi T, Kato S, Divgi C, Kalinsky K, Wei Y, Zhang Y, Borczuk AC, Inoue A, Halmos B and Acharyya $\mathrm{S}$ : An analysis of the relationship between metastases and cachexia in patients with lung cancer. Cancer Med 5: 2641-2648, 2016.

17 Gonlugur U: A retrospective analysis of nutritional parameters in chronic obstructive pulmonary disease between sexes. J Clin Biochem Nutr 41: 175-178, 2007.

18 Zafirova-Ivanovska B, Stojkovikj J, Dokikj D, Anastasova S, Debresliovska A, Zejnel S and Stojkovikj D: The level of cholesterol in COPD patients with severe and very severe stage of the disease. Open Access Maced J Med Sci 4: 277-282, 2016.

19 Kohno M, Okamoto T, Suda K, Shimokawa M, Kitahara H, Shimamatsu S, Konishi H, Yoshida T, Takenoyama M, Yano T and Maehara Y: Prognostic and therapeutic implications of aromatase expression in lung adenocarcinomas with EGFR mutations. Clin Cancer Res 20: 3613-3622, 2014.

20 Narumi T, Arimoto T, Funayama A, Kadowaki S, Otaki Y, Nishiyama S, Takahashi H, Shishido T, Miyashita T, Miyamoto T, Watanabe T and Kubota I: Prognostic importance of objective nutritional indexes in patients with chronic heart failure. $J$ Cardiol 62: 307-313, 2013.
21 Fukushima K, Ueno Y, Kawagishi N, Kondo Y, Inoue J, Kakazu E, Ninomiya M, Wakui Y, Saito N, Satomi S and Shimosegawa T: The nutritional index 'CONUT' is useful for predicting longterm prognosis of patients with end-stage liver diseases. Tohoku J Exp Med 224: 215-219, 2011.

22 Hiura Y, Takiguchi S, Yamamoto K, Takahashi T, Kurokawa Y, Yamasaki M, Nakajima K, Miyata H, Fujiwara Y, Mori M, Kangawa $\mathrm{K}$ and Doki Y: Effects of ghrelin administration during chemotherapy with advanced patients with esophageal cancer: a prospective, randomized, placebo-controlled phase 2 study. Cancer 118: 4785-4794, 2012.

23 Marian AE van Bokhorst-de van der Schueren, Jasper J Quak, B Mary E von Blomberg-van der Flier, Dirk J Kuik, Sterre I Langendoen, Gordon B Snow, Ceri J Green and Paul AM van Leeuwen: Effect of perioperative nutrition, with and without arginine supplementation, on nutritional status, immune function, postoperative morbidity and survival in severely malnourished head and patients with neck cancer. Am J Clin Nutr 92: 11511156, 2010.

24 Buijs N, van Bokhorst-de van der Schueren MA, Langius JA, Leemans CR, Kuik DJ, Vermeulen MA and van Leeuwen PA: Perioperative arginine-supplemented nutrition in malnourished patients with head and neck cancer improves long-term survival. Am J Clin Nutr 92: 1151-1156, 2010.

25 Paccagnella A, Morassutti I and G R: Nutritional intervention for improving treatment tolerance patients with in cancer. Curr Opin Oncol 23: 322-330, 2011.

26 Payne C, Larkin PJ, McIlfatrick S, Dunwoody L and Gracey JH: Exercise and nutrition interventions in advanced lung cancer: a systematic review. Curr Oncol 20: e321-337, 2013.

27 Pardoll DM: The blockade of immune checkpoints in cancer immunotherapy. Nat Rev Cancer 12: 252-264, 2012.

28 Postow MA, Callahan MK and Wolchok JD: Immune checkpoint blockade in cancer therapy. J Clin Oncol 33: 1974-1982, 2015.

29 Postow MA, Chasalow SD, Yuan JD, Kuk D, Panageas KS, Cheng M, Shahabi V, Berman DM and Wolchok JD: Pharmacodynamic effect of ipilimumab on absolute lymphocyte count (ALC) and association with overall survival in patients with advanced melanoma. J Clin Oncol 31: Abst 9052, 2013.

Received March 24, 2017

Revised April 10, 2017

Accepted April 11, 2017 